\title{
Oral Halitosis in Saudi Children
}

\author{
Sarah Mubaraki ${ }^{1 *}$, Rawabi Eskandrani ${ }^{2}$, Rawan Melfi ${ }^{2}$, Razan Alauti ${ }^{2}$ and Mayar Saad Alharbi ${ }^{2}$ \\ ${ }^{1}$ Lecturer, Department of Preventive Dental Sciences, Riyadh Elm University, KSA \\ ${ }^{2}$ Demonestrator, Department of Preventive Dental Sciences, Riyadh Elm University, KSA \\ ${ }^{3}$ General Dentist, KSA
}

Submission: April 15, 2019; Published: April 26, 2019

*Corresponding author: Sarah Mubaraki, Lecturer, Preventive Dental Sciences Department, Pedodontic Division, Riyadh Elm University, Riyadh, KSA

\section{Abstract}

Background: Oral Halitosis $(\mathrm{OH})$ defined as unpleasant oral odor associated with physiological and pathological causes. It is generally accepted that oral cavity is the source of $90 \%$ of halitosis. The aim of our study was to assess the Incidence of oral halitosis in children and evaluate its associated factors.

Methodology: 60 parents respond to the developed questionnaire were distributed to a random selected school in Riyadh city, Saudi Arabia includes demographic data, general health, dental health and dietary habits for their child. Examination included plaque index, dental index (DMFT), and tongue coating and oral halitosis were obtained by organoleptic measurements. Statistical analyses included analysis of variance, frequency, cross-tabulations and Spearman's rho coloration test.

Results: $55 \%$ of the participant had halitosis, a strong relation between halitosis and poor oral hygiene, correlations between several food types and oral malodor were evident.

Conclusion: increased awareness of the importance of oral hygiene and diet is important. Further studies should consider with a larger sample size.

\section{Introduction}

Oral Halitosis $(\mathrm{OH})$ defined as unpleasant oral odor that associated with physiological and pathological causes [1]. OH ranked as the third most common reason for dental visits [2]. Many terminologies have been used in literature as fetor oris [3], fetor ex-ore [4], fetid halitus [5] , oral malodor [6], bad breath [7], OH affects individuals socially creating personal discomfort, social embarrassment and anxiety, which leads to a severe problem causing halitophobia.

More than $50 \%$ of the society suffer from chronic halitosis $[8,9]$. Oral cavity is the source of $90 \%$ of halitosis and can be attributed to deep carious lesion, periodontal disease, impacted food, decreased salivary flow rate and mainly tongue coating [10]. The remainder $10 \%$ originates from underlying systemic diseases such as diabetes mellitus [1], hypertension [11], chronic sinusitis [12], gastrointestinal tract disorders [13] and respiratory disease [14].

Microbial putrefaction of aminoacids such as cystine, cysteine, and methionine by enzymes will produce volatile sulphur compounds (VSCs) such as hydrogen sulphide (H2S), methyl mercap$\tan \left(\mathrm{CH}_{3} \mathrm{SH}\right)$ and dimethyl sulphide $\left[\left(\mathrm{CH}_{3}\right)_{2} \mathrm{~S}\right]$ [5]. Villa et al. found $42.6 \%$ had halitosis [15], Quirynen et al. [16] reported that 76\% had oral causes, $43 \%$ caused by tongue coating, $11 \%$ had periodontal disease (gingivitis/periodontitis) and 18\% had a combi nation [16].Oral halitosis has been widely investigated in adults, only few studies have been carried out in children. The aim of the study was to assess the Incidence of oral halitosis in children and evaluate its associated factors [17-23].

\section{Methodology}

Ethical consideration of this study was obtained from the Research Center of Riyadh Elm University. The sample comprised 60 healthy children randomly selected boys and girls aged from 4 to 6 years, any medically compromised or and any child with dental appliance were excluded from the study.

The study was done in to two stages

\section{a. Stage one:}

An Arabic version of a specially designed self-administered questionnaire, were randomly distributed to 100 , out of which 60 questionnaires were returned and processed for data analysis, the questionnaire involved four major parts; consent form, demographic data (child age, gender, nationality, monthly income, relationship to the child), child general health , child dietary habits and child dental health.

\section{b. Stage two:}

A Complete dental examination was performed based on WHO 
criteria using disposable examination kit (mirror and explorer) and pen light for the 60 children who retained the questionnaire.

The intensity of malodor was detected by the organoleptic test, the child was asked to inhale through the nostril and hold his breath for $1 \mathrm{~min}$ then exhaled the air by the mouth directly on the examiner, air is inhaled from $20 \mathrm{~cm}$. The scoring system is divided into 6 point scale to measure the intensity of halitosis 0 -no odor, 1-barely noticeable,2-slight but clearly noticeable, 3- moderate, 4strong, 5-exteremly strong.

One investigator was trained and calibrated against the lead investigator (SCP).

All statistical analyses were done using SPSS ver 22 data processing software (IBM Corp, Armonk NY, USA). Apart from descriptive statistics, Spearman's rho correlation test was used to determine the relationship between $\mathrm{OH}$ and influencing factors. The probability values ( $\mathrm{P}$-value) of $\mathrm{P}<0.05$ was regarded as significant.

\section{Results}

60 subjects responded to the questionnaire; children aged 4 to 7 years with a mean age of $5.3 \pm 0.76$. More than $60 \%$ of the children thy had three meals per day, The frequency of consumption of meals shows no significant difference $\mathrm{p}=0.721$.

Table 1: $\mathrm{OH}$ in a relation to the diet.

\begin{tabular}{|l|c|c|c|c|c|c|}
\hline & $\begin{array}{c}\text { Gummy } \\
\text { candy }\end{array}$ & Chips & $\begin{array}{c}\text { Garlic \& } \\
\text { onion }\end{array}$ & Candy & $\begin{array}{c}\text { Diary } \\
\text { product }\end{array}$ & $\begin{array}{c}\text { Meat \& } \\
\text { fish }\end{array}$ \\
\hline OH Sig. & 0.032 & 0.1 & 0.013 & 0.028 & 0.381 & 0.161 \\
\hline
\end{tabular}

When oral hygiene factors were tested for any possible association halitosis, there was a significant association between teeth brushing and halitosis $(\mathrm{p}=0.020)$. Statistical significance using Spearman test found when correlating $\mathrm{OH}$ with gummy candy $\mathrm{p}=0.32$, and garlic and onion $\mathrm{p}=0.013$ (Table 1 ).

Table 2: DMFT scores.

\begin{tabular}{|c|c|}
\hline DMFT score & Total $(\mathbf{n}=\mathbf{5 0}) \mathbf{n}(\mathbf{\%})$ \\
\hline 0 & $15(28.8)$ \\
\hline 1 & $7(13.5)$ \\
\hline 2 & $8(15.4)$ \\
\hline 3 & $2(3.8)$ \\
\hline 4 & $6(11.5)$ \\
\hline 5 & $3(5.8)$ \\
\hline 6 & $6(11.5)$ \\
\hline 8 & $2(3.8)$ \\
\hline 10 & $1(1.9)$ \\
\hline
\end{tabular}

When oral hygiene was considered $69.2 \%$ reported brushing their teeth, DMFT was scored from 0 to 10 in (Table 2) While the relationship between $\mathrm{OH}$ and DMFT was found statistically insignificant $\mathrm{p}=0.81$ (Table 2).

\section{Discussion}

The main aim of this study was to assess the incidence of oral halitosis in children and evaluate its associated factors, in order to predict the future health care needs in controlling and solving this social and health problem. Oral halitosis is a noticeable condition that has negative impact on the society. Oral halitosis may affect the social life of the individual limiting his interaction with people, which might lead to anxiety and social isolation. In our study lack of oral hygiene has been implicated in an oral malodor. Our study was aimed at evaluating the incidence of $\mathrm{OH}$ in children and assessing the impact of several factors on oral halitosis. These factors include diet (number of meals, type of food consumed, and the frequency of consumption) and oral hygiene practices.

And Since oral malodor is an olfactory stimulus, direct smelling of the exhaled air by judges is considered the most logical measurement approach so According to Rösing et al organoleptic is considered the gold standard method due to the capability of the human nose to distinguish between pleasant or unpleasant malodor. Using this method, we found $55 \%$ of our sample having $\mathrm{OH}$.

Few studies have documented the prevalence of oral malodor in children. Moreover, there are no data reported on the prevalence of $\mathrm{OH}$ in children in Saudi Arabia nor studies done on the effect of oral hygiene and diet on halitosis.

\section{Conclusion}

Oral halitosis affected more than $50 \%$ of our sample, Halitosis is widespread in the study population, poor oral hygiene and diet are significantly associated with halitosis. Tooth brushing alone is not effective in solving halitosis, so tongue brushing should be part of daily oral hygiene and should be included in the oral hygiene instructions given. Also, health care providers should pay more attention to health education regarding halitosis since halitosis from an extra-oral origin can be the sign of an underlying systemic disease. Therefore, it is substantiated to organize halitosis consultations in a multidisciplinary setting, assembling periodontal problems, and ear-nose-throat specialists, specialists in internal medicine, and psychologists or even psychiatrists.

\section{Conflict of Interest}

The authors declare that there is no conflict of interest and there was no external source of funding for the present study

\section{References}

1. Alshehri FA (2016) Knowledge and attitude of Saudi individuals toward self-perceived halitosis. The Saudi Journal for Dental Research 7(2): 91-95.

2. Loesche WJ, Kazor C (2002) Microbiology and treatment of halitosis. Periodontology 2000 28(1): 256-279.

3. Touyz L, Dent M (1993) Oral malodor: a scientific perspective. Can Dent Assoc 9: 607-610.

4. Almas $\mathrm{K}, \mathrm{Al}$-Hawish $\mathrm{A}, \mathrm{Al}$-Khamis $\mathrm{W}$ (2003) Oral hygiene practices, smoking habit, and self-perceived oral malodor among dental students. J Contemp Dent Pract 4(4): 77-90.

5. Motta LJ, Bachiega JC, Guedes CC, Laranja LT, Bussadori SK (2011) Association between halitosis and mouth breathing in children. Clinics 66(6): 939-942. 
6. Tas A, Köklü S, Yüksel I, Başar Ö, Akbal E, Ahmet C (2011) No significant association between halitosis and upper gastrointestinal endoscopic findings: a prospective study. Chin Med J (Engl) 124(22): 3707-3710.

7. Kapoor U, Sharma G, Juneja M, Nagpal A (2016) Halitosis: Current concepts on etiology, diagnosis and management. Eur J Dent 10(2): 292300.

8. Lee HJ, Kim HM, Kim N, Oh JC, Jo HJ, et al. (2014) Association between halitosis diagnosed by a questionnaire and halimeter and symptoms of gastroesophageal reflux disease. J Neurogastroenterol Motil 20(4): 483-490.

9. Arora L, Sharma A (2012) A Study to find out the Dental and Associated Psychosocial Factors in Patients of Halitosis. Delhi Psychiatry Journal 15(1): 122-129.

10. Cortelli JR, Barbosa MDS, Westphal MA (2008) Halitosis: a review of associated factors and therapeutic approach. Braz Oral Res 22(1): 44-54.

11. Han JS, Hong JH, Choi JS (2011) Factors associated with self-assessment of halitosis in adult. The Journal of the Korea Contents Association 11(12): 347-356.

12. Al-Ansari JM, Boodai H, Al-Sumait N, Al-Khabbaz AK, Al-Shammari KF, et al. (2006) Factors associated with self-reported halitosis in Kuwaiti patients. J Dent 34(7): 444-449.

13. Kinberg S, Stein M, Zion N, Shaoul R (2010) The gastrointestinal aspects of halitosis. Can J Gastroenterol 24(9): 552-556.

14. Attia EL, Marshall KG (1982) Halitosis. Can Med Assoc J 126(11): 12811285.

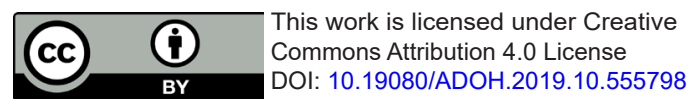

15. Villa A, Zollanvari A, Alterovitz G, Cagetti M, Strohmenger L, et al. (2014) Prevalence of halitosis in children considering oral hygiene, gender and age. Int J Dent Hyg 12(3): 208-212.

16. Quirynen M, Dadamio J, Van den Velde S, De Smit M, Dekeyser C, et al. (2009) Characteristics of 2000 patients who visited a halitosis clinic. Journal of clinical periodontology 36(11): 970-975.

17. Aylıkc BU, Colak H (2013) Halitosis: From diagnosis to management. J Nat Sci Biol Med 4(1): 14-23.

18. Ren W, Xun Z, Wang Z, Zhang Q, Liu X, et al. (2016) Tongue Coating and the Salivary Microbial Communities Vary in Children with Halitosis. Sci Rep 6: 24481.

19. Nadanovsky P, Carvalho L, Ponce de Leon A (2007) Oral malodour and its association with age and sex in a general population in Brazil. Oral Dis 13(1): 105-109.

20. Saito H, Kawaguchi Y (2002) Halitosis prevention campaign: a report of oral health promotion activities in Japan. Int Dent J 52(S5P1): 197-200.

21. Liu XN, Shinada K, Chen XC, Zhang BX, Yaegaki K, et al. (2006) Oral malodor-related parameters in the Chinese general population. J Clin Periodontol 33(1): 31-36.

22. Kim SY, Sim S, Kim SG, Park B, Choi HG (2015) Prevalence and associated factors of subjective halitosis in Korean adolescents. PloS one 10(10): e0140214.

23. Rösing CK1, Loesche W (2011) Halitosis: an overview of epidemiology, etiology and clinical management. Braz Oral Res 25(5): 466-471.

Your next submission with Juniper Publishers will reach you the below assets

- Quality Editorial service

- Swift Peer Review

- Reprints availability

- E-prints Service

- Manuscript Podcast for convenient understanding

- Global attainment for your research

- Manuscript accessibility in different formats

( Pdf, E-pub, Full Text, Audio)

- Unceasing customer service

Track the below URL for one-step submission

https://juniperpublishers.com/online-submission.php 